\title{
Adherence to reduced-polluting biomass fuel stoves improves respiratory and sleep symptoms in children
}

\author{
Roberto A Accinelli1 ${ }^{1,23^{*}}$, Oscar Llanos ${ }^{1}$, Lidia M López ' María I Pino ${ }^{1}$, Yeny A Bravo ${ }^{1,2,3}$, Verónica Salinas ${ }^{1}$,

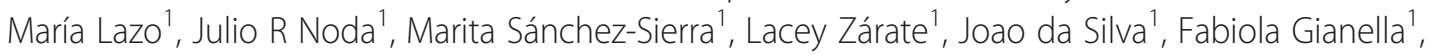 \\ Leila Kheirandish-Gozal ${ }^{4,5}$ and David Gozal| ${ }^{4, *^{*}}$
}

\begin{abstract}
Background: Symptoms of sleep apnea are markedly increased in children exposed to smoke from biomass fuels and are reduced by kitchen stoves that improve indoor biomass pollution. However, the impact of adherence to the use of improved stoves has not been critically examined.

Methods: Sleep-related symptom questionnaires were obtained from children $<15$ years of age in 56 families residing in the communities of Lliupapuquio, Andahuaylas province in Peru before and 2 years after installation of less-polluting Inkawasi cooking stoves.

Results: 82 children with lifetime exposures to indoor fuel pollution were included. When compared to those alternating between both types of stoves or those using traditional stoves only, those children who exclusively used Inkawasi cooking stoves showed significant improvements in sleep and respiratory related symptoms, but some minor albeit significant improvements occurred when both stoves were concomitantly used.
\end{abstract}

Conclusions: Improvements in respiratory and sleep-related symptoms associated with elevated indoor biomass pollution occur only following implementation and exclusive utilization of improved kitchen stoves.

Keywords: Biomass fuel pollution, Sleep, Respiration, Kitchen stoves

\section{Background}

Indoor biomass pollution is one of the most important sources of pollution particularly in the developing world. [1] Indoor fuel sources can be either solid, liquid, or gas combustibles, with biomass fuel and coal constituting by far the most frequently used solid fuels. Biomass fuel refers to plant or animal-derived material products (wood, agriculture waste, and dung) burned for cooking or heating purposes. [2,3] In 2007, solid fuel was used in $42 \%$ of all households worldwide, and in $76 \%$ of rural households. [4] In developing countries, women and young children are the most exposed to this form of air pollution because

\footnotetext{
* Correspondence: roberto.accinelli@upch.pe; dgozal@uchicago.edu 'Laboratorio de Respiración del Instituto de Investigaciones de la Altura, Universidad Peruana Cayetano Heredia, Lima, Perú

${ }^{4}$ Section of Pediatric Sleep Medicine, Department of Pediatrics, and Comer Children's Hospital, Pritzker School of Medicine, The University of Chicago,

Chicago, IL, USA

Full list of author information is available at the end of the article
}

they spend the greatest proportion of time near the domestic hearth, while this is further exacerbated in highland areas, since people spend more time indoors because of the cold climate [5-8].

In-house exposures to biomass pollution have been associated with an increased prevalence of lung diseases, including COPD [9-17], recurrent acute respiratory tract infections in children [18-20], lung cancer [21], asthma [22,23], tuberculosis [24-26], interstitial lung disease [27,28] and non pulmonary disease, such as cataracts, nasopharyngeal cancer, ischemic heart disease and cor pulmonale [29]. However, the potential associations between biomass indoor pollution and sleep-disordered-breathing (SDB) have not been as extensively explored. Indeed, in a recent study from our group, we showed a significant increase in the prevalence of symptoms of SDB in children exposed to indoor biomass fuel pollution [30]. However, the impact of adherence to implementation and installation of higher

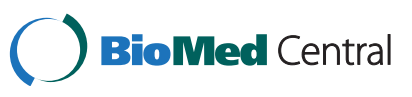


efficiency home based stoves that reduce indoor pollution was not examined. In this context, we took advantage of an initiative aimed at replacing conventional home based stoves with modified kitchen stoves that reduce biomass indoor pollution by more than $95 \%$ to assess the impact of such intervention on sleep and SDB symptoms, while monitoring adherence to such intervention.

\section{Methods}

The study was approved by the Human Subject Ethics Committee of the University Cayetano Heredia (registration code \#56758). Informed consent was obtained from the parents, and age appropriate assent was also obtained from the children. We performed a prospective survey of residents in Lliupapuquio, Andahuaylas-Peru, a small village located at 3557 meters above sea level, who were beneficiaries of Program Juntos, a Peruvian National initiative against poverty. We included children less than 15 years of age, who had a lifetime exposure to traditional high biomass pollution generating home kitchen stoves. A total of 56 families were identified during a pilot phase intervention to install the Inkawasi stove, a Peruvian designed stove with an external exhaust that has conclusively been demonstrated to reduce particulate matter concentrations (PM 2.5) by $74 \%$ when compared to traditional stoves, while using 50\% less wood combustible material, as well as displaying a superior safety profile during daily use [31].

Two years after the installation and after confirming the adequate operation of the new stoves, we performed a follow-up survey. In the village, a proportion of the families who received the Inkawasi stoves never used them and preferred to continue using their traditional stoves. A second group opted for the concomitant use of either the traditional stoves or the new stoves, and a third group of families exclusively used the new Inkawasi stoves.

Both pre- and post-intervention surveys were conducted through a structured interview of the parents, using a previously validated questionnaire [32-34]. This questionnaire is particularly focused on respiratory and sleep-associated disorders and their symptoms. However, we did not implement any specific preferential weighting of questionnaire items as previously reported in a US-based population [34]. The major questions for this study included whether the child snored or not, and if so, the severity of snoring (loudness and frequency). All sleep-related questions used Likert-type responses "never" [0], "rarely" (once per week) [1], "occasionally" (twice per week) [2], "frequently" (three to four times per week) [3], and "almost always" ( $>4$ times per week) [4] for the preceding 3-month timeframe. The overall scores to problems during sleep were designated from each of the answers to questions pertaining to sleep and divided by the number of questions. Other answer categories of Likert-type order were for bedtime:
“7:00-8:00 p.m.," "8:00-9:00 p.m.," “9:00- 10 p.m.," "10:00-11:00 p.m.", and "after 10 p.m."; for wake up time: "5:00-6:00 a.m.," "6:00-6:30 a.m.," "6:30-7 a.m.," "7:007:30 a.m." and "after 7:30 a.m."; for loudness of snoring: "mildly quiet" [0], "medium loud" [1], "loud" [2], "very loud" [3], "extremely loud" [4]; for child's room: "sleep alone," "share with 1," "share with 2," "share with 3," and "share with $>3$ "; and for all other items binary answer categories were applied. Likert values were treated as continuous variables for comparison purposes, and response scores addressing related symptoms were collapsed and treated as a single score.

Questions on adherence regarding the use of new improved stoves were developed and implemented only during the follow-up visit.

Data were analyzed using SPSS statistical software (version 17.0, Chicago, IL). McNemar tests or Chi-square test with Fisher Exact correction were used to perform paired comparisons of qualitative variables before and after kitchen stove change. A p-value of less than 0.05 was considered to be statistically significant.

\section{Results}

Eighty-two children with lifetime exposures to biomass fuel indoor pollution were included. The mean age was $8.3 \pm 3.2$ years, ranging from 2 to 14 years, and the cohort included 40 boys (48.8\%). Of the 82 children, 38 were in households in which only the new Inkawasi stove stoves were available, 19 had access to both the Inkawasi stoves and traditional stoves operating concomitantly in their houses, and 25 children continued to exclusively use the traditional stoves despite having the new Inkawasi stoves installed.

The prevalence of respiratory symptoms for the whole cohort was very high during the initial visit as follows: nasal congestion $(40 \%)$, frequent colds (41.3\%), hyperactivity $(26.9 \%)$, frequent repetitive movements during sleep (35.4\%), sore throat (38\%), night time awakenings (42.3\%), daytime sleepiness $(21.8 \%)$, and falling asleep at school (11.7\%). In follow-up survey, when the 25 children who did not use the new Inkawasi kitchen stoves were omitted from the analyses (Table 1), the remaining 57 children demonstrated statistically significant reductions in the frequency of sore throat ( $44.4 \%$ vs. $25.9 \%$; $\mathrm{p}<0.05)$, headache at awakening $(43.4 \%$ vs. $22.6 \% ; \mathrm{p}<0.05)$, and nightmares $(48.1 \%$ vs. $25.9 \%$; p < 0.05). A statistically significant improvement in easiness to fall asleep was also found $(29.6 \%$ vs. $55.6 \% \mathrm{p}<0.01)$. When the 19 children who were not exclusively using the modified stove were further excluded from the intervention group, the remaining 38 children continued to demonstrate improvements in ease to fall asleep $(19.4 \%$ vs. $50 \%$; p $<0.02)$, and in the frequency of sore throat symptoms $(47.2 \%$ vs. $22.2 \%$; p $<0.05)$, as well as improvements in the willingness to go to sleep $(51.4 \%$ vs. $77.1 \%$; $\mathrm{p}$ 0.05) (Table 1). In fact, the children who 
Table 1 Effects of frequency of use of improved Inkawasi cooking stoves on the itemized symptoms included in the questionnaire before and 2 years after stove installation

\begin{tabular}{|c|c|c|c|c|c|c|c|c|c|c|c|c|c|c|c|}
\hline \multirow[t]{3}{*}{ Symptom } & \multicolumn{5}{|c|}{$\begin{array}{l}\text { Improved Inkawasi } \\
\text { stove use only } \\
(n=38)\end{array}$} & \multicolumn{5}{|c|}{$\begin{array}{l}\text { Traditional stove } \\
\text { use only } \\
(n=25)\end{array}$} & \multicolumn{5}{|c|}{$\begin{array}{l}\text { Mixed Inkawasi and } \\
\text { traditional stove use } \\
\qquad(n=19)\end{array}$} \\
\hline & \multicolumn{2}{|c|}{ Before } & \multicolumn{2}{|c|}{ After } & \multirow[t]{2}{*}{$p$ value } & \multicolumn{2}{|c|}{ Before } & \multicolumn{2}{|c|}{ After } & \multirow[t]{2}{*}{$p$ value } & \multicolumn{2}{|c|}{ Before } & \multicolumn{2}{|c|}{ After } & \multirow[t]{2}{*}{$\mathrm{p}$ value } \\
\hline & $n$ & $\%$ & $n$ & $\%$ & & $n$ & $\%$ & $n$ & $\%$ & & $n$ & $\%$ & $n$ & $\%$ & \\
\hline Reduced appetite & 16 & 47.1 & 15 & 44.1 & & 17 & 70.8 & 15 & 62.5 & & 6 & 35.3 & 6 & 35.3 & \\
\hline Ear infections & 4 & 12.1 & 5 & 15.2 & & 2 & 9.5 & 4 & 19 & & 3 & 16.7 & 0 & 0 & \\
\hline Frequent colds & 18 & 54.5 & 11 & 33.3 & & 11 & 45.8 & 7 & 29.2 & & 2 & 11.1 & 4 & 22.2 & \\
\hline Nasal congestion & 17 & 50 & 13 & 38.2 & & 7 & 29.2 & 9 & 37.5 & & 6 & 35.3 & 1 & 5.9 & \\
\hline Attention deficits & 16 & 48.5 & 11 & 33.3 & & 13 & 54.2 & 5 & 20.8 & & 9 & 50 & 5 & 27.8 & \\
\hline Hyperactivity & 10 & 28.6 & 11 & 31.4 & & 7 & 28 & 9 & 36 & & 4 & 22.2 & 8 & 44.4 & \\
\hline Snoring & 4 & 11.4 & 4 & 11.4 & & 7 & 28 & 6 & 24 & & 2 & 11.1 & 4 & 22.2 & \\
\hline Repetitive movements during sleep & 11 & 30.6 & 18 & 50 & & 7 & 28 & 9 & 36 & & 10 & 55.6 & 8 & 44.4 & \\
\hline Problems during sleep & 20 & 53.9 & 1 & 2.6 & $<0.0005$ & 5 & 20.8 & 5 & 20.8 & & 10 & 52.6 & 1 & 5.3 & $<0.005$ \\
\hline Respiratory effort during sleep & 3 & 8.8 & 2 & 5.9 & & 0 & 0 & 3 & 12.5 & & 0 & 0 & 1 & 5.6 & \\
\hline Stops breathing during sleep & 4 & 11.8 & 2 & 5.9 & & 1 & 4.2 & 2 & 8.3 & & 1 & 5.6 & 2 & 11.1 & \\
\hline Needs being shaken to breathe during sleep & 2 & 6.1 & 4 & 12.1 & & 2 & 8.7 & 3 & 13 & & 1 & 5.9 & 0 & 0 & \\
\hline Ease falling asleep & 7 & 19.4 & 19 & 50 & $<0.02$ & 9 & 37.5 & 14 & 58.3 & & 9 & 50 & 12 & 66.7 & \\
\hline Sore throat & 17 & 47.2 & 8 & 22.2 & $<0.05$ & 6 & 24 & 7 & 28 & & 7 & 38.9 & 6 & 33.3 & \\
\hline Enuresis & 4 & 11.1 & 5 & 13.9 & & 6 & 24 & 4 & 16 & & 4 & 22.2 & 2 & 11.1 & \\
\hline Wakes up to urinate & 13 & 35.1 & 15 & 40.5 & & 9 & 36 & 13 & 52 & & 10 & 55.6 & 8 & 44.4 & \\
\hline Easiness to wake up & 21 & 56.8 & 30 & 80.7 & $<0.05$ & 13 & 54.2 & 21 & 87.5 & $<0.04$ & 9 & 50 & 10 & 55.6 & \\
\hline Willingness to go to bed & 18 & 51.4 & 27 & 77.1 & $<0.05$ & 21 & 84 & 20 & 80 & & 12 & 66.7 & 11 & 61.1 & \\
\hline Not rested after sleep & 11 & 30.6 & 15 & 41.7 & & 4 & 16 & 6 & 24 & & 2 & 11.1 & 4 & 22.2 & \\
\hline Wakes up during the night & 15 & 42.9 & 7 & 20 & & 9 & 36 & 10 & 40 & & 9 & 50 & 10 & 55.6 & \\
\hline Speaks during sleep & 12 & 34.3 & 10 & 28.6 & & 11 & 44 & 10 & 40 & & 4 & 22.2 & 5 & 27.8 & \\
\hline Sleepwalking & 1 & 2.8 & 1. & 2.8 & & 2 & 8 & 1 & 4 & & 2 & 11.1 & 0 & 0 & \\
\hline Sits while asleep & 5 & 14.3 & 3 & 8.6 & & 5 & 20.8 & 3 & 12.5 & & 2 & 11.1 & 3 & 16.7 & \\
\hline Nightmares & 17 & 47.2 & 10 & 27.8 & & 12 & 48 & 8 & 32 & & 9 & 50 & 4 & 22.2 & \\
\hline Morning headache & 15 & 41.7 & 6 & 19.8 & $<0.02$ & 7 & 28 & 7 & 28 & & 8 & 47.1 & 6 & 32.6 & \\
\hline Mouth breathing & 5 & 13.9 & 5 & 13.9 & & 2 & 8 & 3 & 12 & & 2 & 11.1 & 0 & 0 & \\
\hline Daytime sleepiness & 7 & 20 & 8 & 22.9 & & 6 & 24 & 6 & 24 & & 4 & 22.2 & 0 & 0 & \\
\hline Sleepiness at school & 4 & 11.8 & 3 & 8.8 & & 4 & 16 & 3 & 12 & & 1 & 5.6 & 0 & 0 & \\
\hline Worried about sleep problems & 3 & 8.8 & 4 & 11.8 & & 4 & 18.2 & 0 & 0 & & 0 & 0 & 2 & 11.1 & \\
\hline
\end{tabular}

exclusively used the improved Inkawasi kitchen stoves exhibited significant improvements in the largest number of questionnaires items $(n=6 / 28$; Table 1$)$ compared to those alternating use of the 2 stoves $(n=1 / 28 ; \mathrm{p}<0.05)$, as well as those not using the improved stoves $(0 / 28 ; \mathrm{p}<0.02)$.

\section{Discussion}

In the present study, we confirm previous findings that children who have endured lifelong exposures to biomass fuel indoor pollution display an inordinately high prevalence of sleep and respiratory symptoms, including SDB symptoms [30]. Furthermore, we now show that the magnitude of improvement in a selected number of these symptoms, particularly sleep-related symptoms, emerges only after changing the stoves to those with improved, less polluting characteristics. Interestingly, even partial use of the new and improved Inkawasi stove was associated with some degree of improvements, albeit not as prominent or extensive as those occurring when the new improved stoves were exclusively used.

In the context of the current study, we found a remarkably similar prevalence of respiratory and sleep symptoms when compared to our previous study with the exception of snoring (16.7\% vs. 52.5\%) [30]. However, the magnitude 
of the reduction of those symptoms in the present study was not as prominent, even though the same survey tool was used, and children in both studies had similar ages and ethnicity. Therefore, it is possible that the differences in response may reflect the mixed utilization patterns of the new stoves in the present study compared to the comprehensive implementation of the Inkawasi stove in our previous intervention [30].

In a parallel study of this population, the degree of indoor pollution was markedly reduced when consistent, correct, and exclusive use of the improved Inkawasi kitchen stoves was implemented. Compared to traditional stoves, the particulate matter concentration levels decreased by $74 \%$ and the CO concentration level decreased by $97 \%$. Of the new stoves installed here, we found that one year after installation, 78\% had deteriorated grills, and $61 \%$ had deteriorated combustion chambers, both of these factors clearly reducing the efficiency of the new stoves. As such, the differences in the responses recorded in this study and the preceding study probably reflect some of these technical and equipment-related issues. Appropriate utilization and maintenance of the higher efficiency stoves are critically important factors for the correct operation of the stoves, and for the anticipated emergence of improvements in respiratory symptoms. In a study performed in African children who intermittently cooked inside their residences or outdoors, cooking with solid fuels in the absence of a chimney or hood was associated with a statistically significant adjusted hazard ratio of 2.68 (95\% CI: 1.38 to 5.23) for the emergence of symptoms of respiratory infection. Although outdoor cooking is less harmful than indoor cooking, overall, stove ventilation efficiency emerges as the most significant determinant of acute lower respiratory infection mortality [35]. Similar studies have been reported in other countries, such as in India [36], Nepal [37] and Pakistan [38]. In a 2011 meta-analysis of 25 studies, the overall pooled odds ratios indicate significant associations between indoor biomass fuel pollution and acute respiratory infection in children (OR 3.53, 95\% CI 1.94 to 6.43) [23]. In our study, a most salient finding was that compliance in the use of the improved stoves was a major determinant of the outcomes associated with the stove replacement intervention. In addition to the correct and exclusive use of the Inkawasi stoves, appropriate maintenance of such stoves over time appears to be important in securing improved outcomes.

Some limitations of the present study deserve mention. First, the study did not implement any objective measures of sleep or lung function, and such approach would clearly be needed in future studies. Secondly, quantitative monitoring of environmental pollution in each of the households throughout the duration of the study would be desirable and is planned in the context of subsequent initiatives aiming to further spread the implementation of reduced biomass in-house pollution in poor villages. Finally, the study was not powered to identify differences in most of the questionnaire items, since the frequency of positive responses for several of the questionnaire items in the pre-implementation group was low, and therefore given the small number of children in all 3 groups, demonstration of a statistically significant decrease would be precluded under such circumstances.

\section{Conclusions}

In summary, the improvements in sleep-related symptoms as previously observed following adequate and supervised implementation of modified kitchen-stoves were not as significant without the correct and exclusive use of such less-polluting stoves. Reduced adherence to the use of improved stoves for biomass fuels and inadequate operation and maintenance of the stoves emerged as determining factors associated with reduced effectiveness of the intervention. There is no doubt that changing from traditional biomass fuel stoves to improved less polluting stoves is of main importance in reducing indoor air pollution associated symptoms. However, such interventions need to be coupled with implementation of measures that will ensure permanent and exclusive use of the new stoves along with appropriate maintenance training. Otherwise, such wellintentioned programs aiming to reduce sleep and respiratory morbidity due to biomass fuel indoor pollution may either fail or underperform.

\section{Competing interests}

The authors declare that they have no competing interests.

\section{Authors' contributions}

All of the authors have made substantial contributions to the study. RAA: conception and design of the study, interpretation of data, and drafting of the article. OL: analysis and interpretation of data, and drafting the article. LL: design of the study, acquisition of data, and drafting of the article. YB, VS, $M L, J N, M S-S, L Z$, JS and FG: design of the study and acquisition of data. LKG and DG performed critical evaluation and interpretation of the data, and revised the manuscript critically for important intellectual content. All authors have reviewed and approved the final version of the manuscript.

\section{Financial support}

The study was funded by Deutsche Gesellschaft für Internationale Zusammenarbeit GIZ (German Society for International Cooperation), National Programme for support the poorest-JUNTOS (Government of Peru) and Global Cooperation Energy and Climate Change (Government of Holland). The funder did not have any role in the study design, analysis, interpretation or dissemination of research findings.

\section{Author details}

${ }^{1}$ Laboratorio de Respiración del Instituto de Investigaciones de la Altura, Universidad Peruana Cayetano Heredia, Lima, Perú. ${ }^{2}$ Hospital Nacional Cayetano Heredia, Lima, Perú. ${ }^{3}$ Facultad de Medicina Alberto Hurtado, Universidad Peruana Cayetano Heredia, Lima, Perú. ${ }^{4}$ Section of Pediatric Sleep Medicine, Department of Pediatrics, and Comer Children's Hospital, Pritzker School of Medicine, The University of Chicago, Chicago, IL, USA. ${ }^{5}$ Department of Pediatrics, University of Chicago, 5721 S. Maryland Avenue, MC 8000, Suite K-160, Chicago, IL 60637, USA.

Received: 15 August 2013 Accepted: 14 January 2014

Published: 17 January 2014 


\section{References}

1. Sood A: Indoor fuel exposure and the lung in both developing and developed countries: an update. Clin Chest Med 2012, 33:649-665.

2. Kodgule R, Salvi S: Exposure to biomass smoke as a cause for airway disease in women and children. Curr Opin Allergy Clin Immunol 2012, 12:82-90.

3. Kim KH, Jahan SA, Kabir E: A review of diseases associated with household air pollution due to the use of biomass fuels. $J$ Hazard Mater 2011, 192:425-431

4. World Health Organization: World health statistics, 2010. Geneva (Switzerland): World Health Organization; 2010

5. Armstrong JR, Campbell H: Indoor air pollution exposure and lower respiratory infections in young Gambian children. Int J Epidemiol 1991 20:424-429.

6. Ezzati M, Lopez AD, Rodgers A, Vander Hoorn S, Murray CJ, Comparative Risk Assessment Collaborating Group: Selected major risk factors and global and regional burden of disease. Lancet 2002, 360:1347-1360.

7. Davidson Cl, Lin SF, Osborn JF, Pandey MR, Rasmussen RA, Khalil MA Indoor and outdoor air pollution in the Himalayas. Environ Sci Technol 1986, 20:561-567.

8. Rinne ST, Rodas EJ, Rinne ML, Simpson JM, Glickman LT: Use of biomass fuel is associated with infant mortality and child health in trend analysis. Am J Trop Med Hyg 2007, 76:585-591.

9. Dennis RJ, Maldonado D, Norman S, Baena E, Martinez G: Wood smoke exposure and risk for obstructive airways disease among women. Chest 1996, 109:115-119.

10. Dutt D, Srinivasa DK, Rotti SB, Sahai A, Konar D: Effect of indoor air pollution on the respiratory system of women using different fuels for cooking in an urban slum of Pondicherry. Natl Med J India 1996, 9:113-117.

11. Fullerton DG, Suseno A, Semple S, Kalambo F, Malamba R, White S, Jack S, Calverley PM, Gordon SB: Wood smoke exposure, poverty and impaired lung function in Malawian adults. Int J Tuberc Lung Dis 2011, 15:391-398.

12. Golshan M, Faghihi M, Marandi MM: Indoor women jobs and pulmonary risks in rural areas of Isfahan, Iran, 2000. Respir Med 2002, 96:382-388.

13. Kurmi OP, Devereux GS, Smith WC, Semple S, Steiner MF, Simkhada P, Lam KB, Ayres JG: Reduced lung function due to biomass smoke exposure in young adults in rural Nepal. Eur Respir J 2013, 41:25-30.

14. Caballero A, Torres-Duque CA, Jaramillo C, Bolívar F, Sanabria F, Osorio P, Orduz C, Guevara DP, Maldonado D: Prevalence of COPD in five Colombian cities situated at low, medium, and high altitude (PREPOCOL study). Chest 2008, 133:343-349.

15. Regalado J, Perez-Padilla R, Sansores R, Páramo Ramirez Jl, Brauer M, Paré P, Vedal S: The effect of biomass burning on respiratory symptoms and lung function in rural Mexican women. Am J Respir Crit Care Med 2006, 174:901-905.

16. Chapman RS, He X, Blair AE, Lan Q: Improvement in household stoves and risk of chronic obstructive pulmonary disease in Xuanwei, China: retrospective cohort study. BMJ 2005, 331:1050

17. Perez-Padilla R, Regalado J, Vedal S, Paré P, Chapela R, Sansores R, Selman M: Exposure to biomass smoke and chronic airway disease in Mexican women. A case-control study. Am J Respir Crit Care Med 1996, 154:701-706.

18. Morris K, Morgenlander M, Coulehan JL, Gahagen S, Arena VC: Woodburning stoves and lower respiratory tract infection in American Indian children. Am J Dis Child 1990, 144:105-108.

19. Simoni M, Scognamiglio A, Carrozzi L, Baldacci S, Angino A, Pistelli F, Di Pede F, Viegi G: Indoor exposures and acute respiratory effects in two general population samples from a rural and an urban area in Italy. J Expo Anal Environ Epidemiol 2004, 14(Suppl 1):S144-S152.

20. Behera $D$, Balamugesh $T$ : Indoor air pollution as a risk factor for lung cancer in women. J Assoc Physicians India 2005, 53:190-192.

21. Hosgood HD 3rd, Boffetta P, Greenland S, Lee YC, McLaughlin J, Seow A, Duell EJ, Andrew AS, Zaridze D, Szeszenia-Dabrowska N, Rudnai P, Lissowska J, Fabiánová E, Mates D, Bencko V, Foretova L, Janout V, Morgenstern H, Rothman N, Hung RJ, Brennan P, Lan Q: Inhome coal and wood use and lung cancer risk: a pooled analysis of the International Lung Cancer Consortium. Environ Health Perspect 2010, 118:1743-1747.

22. Epton MJ, Dawson RD, Brooks WM, Kingham S, Aberkane T, Cavanagh JA, Frampton CM, Hewitt T, Cook JM, McLeod S, McCartin F, Trought K, Brown L: The effect of ambient air pollution on respiratory health of school children: a panel study. Environ Health 2008, 7:16.
23. Po JY, FitzGerald JM, Carlsten C: Respiratory disease associated with solid biomass fuel exposure in rural women and children: systematic review and meta-analysis. Thorax 2011, 66:232-239.

24. Mishra VK, Retherford RD, Smith KR: Cooking with biomass fuels increases the risk of tuberculosis. Natl Fam Health Surv Bull 1999, 13:1-4

25. Mishra VK, Retherford RD, Smith KR: Biomass cooking fuels and prevalence of tuberculosis in India. Int J Infect Dis 1999, 3:119-129.

26. Slama K, Chiang CY, Hinderaker SG, Bruce N, Vedal S, Enarson DA: Indoor solid fuel combustion and tuberculosis: is there an association? Int J Tuberc Lung Dis 2010, 14:6-14.

27. Churg A, Myers J, Suarez T, Gaxiola M, Estrada A, Mejia M, Selman M: Airway-centered interstitial fibrosis: a distinct form of aggressive diffuse lung disease. Am J Surg Pathol 2004, 28:62-68.

28. Ramage JE Jr, Roggli VL, Bell DY, Piantadosi CA: Interstitial lung disease and domestic wood burning. Am Rev Respir Dis 1988, 137:1229-1232.

29. Sandoval J, Salas J, Martinez-Guerra ML, Gómez A, Martinez C, Portales A, Palomar A, Villegas M, Barrios R: Pulmonary arterial hypertension and cor pulmonale associated with chronic domestic wood smoke inhalation. Chest 1993, 103:12-20

30. Castañeda JL, Kheirandish-Gozal L, Gozal D, Accinelli RA, The Pampa Cangallo Instituto de Investigaciones de la Altura Research Group: Effect of reductions in biomass fuel exposure on symptoms of sleep apnea in children living in the peruvian andes: a preliminary field study. Pediatr Pulmonol 2013, 48:996-999.

31. Informe de verificación y evaluación de concentración de PM 2.5 y CO intradomiciliarias de las cocinas mejoradas instaladas en el centro poblado de Lliupapuquio. San Jerónimo, Andahuaylas: SENCICO; 2011.

32. Gozal D: Sleep-disordered breathing and school performance in children. Pediatrics 1998, 102:616-620

33. Montgomery-Downs HE, O'Brien LM, Holbrook CR, Gozal D: Snoring and sleep-disordered breathing in young children: subjective and objective correlates. Sleep 2004, 27:87-94.

34. Spruyt K, Gozal D: Screening of pediatric sleep-disordered breathing: aproposed unbiased discriminative set of questions using clinical severity scales. Chest 2012, 142:1508-1515.

35. Rehfuess EA, Tzala L, Best NJ, Briggs DJ, Joffe M: Solid fuel use and cooking practices as a major risk factor for ALRI mortality among African children. Epidemiol Community Health 2009, 63:887-892.

36. Patel AB, Dhande LA, Pusdekar YV, Borkar JA, Badhoniya NB, Hibberd PL: Childhood illness in households using biomass fuels in India: secondary data analysis of nationally representative national family health surveys. Occup Environ Health 2013, 19:35-42.

37. Bates MN, Chandyo RK, Valentiner-Branth P, Pokhrel AK, Mathisen M, Basnet S, Shrestha PS, Strand TA, Smith KR: Acute lower respiratory infection in childhood and household fuel use in Bhaktapur, Nepal. Environ Health Perspect 2013: [Epub ahead of print].

38. Janjua NZ, Mahmood B, Dharma VK, Sathiakumar N, Khan MI: Use of biomass fuel and acute respiratory infections in rural Pakistan. Public Health 2012, 126:855-862.

\section{doi:10.1186/1471-2431-14-12}

Cite this article as: Accinelli et al:: Adherence to reduced-polluting biomass fuel stoves improves respiratory and sleep symptoms in children. BMC Pediatrics 2014 14:12.

\section{Submit your next manuscript to BioMed Central and take full advantage of:}

- Convenient online submission

- Thorough peer review

- No space constraints or color figure charges

- Immediate publication on acceptance

- Inclusion in PubMed, CAS, Scopus and Google Scholar

- Research which is freely available for redistribution 